\title{
Outcomes Comparison of the Veterans' Choice Program With the Veterans Affairs Health Care System for Hepatitis C Treatment
}

Daniel Chao, MD; Hema Buddha; Chitra Damodaran, MD; Linda Tran, PharmD; Richard Strong, MD; and Christian S. Jackson, MD

Background: The US Department of Veterans Affairs (VA) has been stressed by the large number of veterans requiring direct-acting antiviral (DAA) medications for hepatitis $\mathrm{C}$ virus (HCV) treatment. The Veterans Choice Program provides VA patients more options to receive treatment. This study compared the experience of veterans who received HCV treatment through the Veterans Choice Program and those that received treatment at the VA Loma Linda Healthcare System (VALLHCS) in fiscal year (FY) 2016.

Methods: A chart review was performed on all veterans referred by VALLHCS to Choice for HCV treatment during FY 2016, and matched to veterans who received treatment at VALLHCS. Data collected included Fibrosis-4 score (Fib-4), platelet count, days elapsed between time of referral and time of appointment (wait time), rate of sustained virologic response at 12 weeks (SVR12), reason for treatment failure, and cost effectiveness.
Results: One hundred veterans were referred to Choice; 71 were seen at least once by a Choice provider, and 61 completed a treatment course. Mean Fib-4 and platelet count was 1.9 and 228,000 for the Choice population and 3.4 and 158,000 for the VALLHCS population, respectively. There was no difference in SVR12 rate. Mean wait time was 42 days for Choice vs 29 days for VALLHCS $(P<.001)$. Choice health care providers incurred a mean $\$ 8,561.40$ in additional costs per veteran seen.

Conclusions: While treatment success rates were similar between Choice and VALLHCS, the degree of liver fibrosis was more advanced in the VALLHCS population. The wait time for care was longer with Choice compared with a direct referral within the VA. While Choice offers a potential solution to providing care for veterans, the current program has unique problems that must be considered.
Daniel Chao, Chitra Damodaran, Richard Strong, and Christian Jackson are Physicians; and Linda Tran is a Pharmacist; all in the Gastroenterology Section at VA Loma Linda Healthcare System in California. Hema Buddha is a Clinical Research Program Administrator at the University of California, Riverside. Daniel Chao, Chitra Damodaran, and Christian Jackson are Assistant Professors of Medicine and Richard Strong is an Associate Professor of Medicine, at Loma Linda University in California.

Correspondence:

Daniel Chao

(daniel.chao@va.gov)
D opulation studies show high prevalence of chronic hepatitis $\mathrm{C}$ virus (HCV) infection among veterans, especially Vietnam War era veterans. ${ }^{1,2}$ The development of safe and efficacious direct-acting antiviral (DAA) medications to treat $\mathrm{HCV}$ infection made the majority of those infected eligible for treatment. However, the large number of veterans needing DAA treatment stressed the resources of the US Department of Veterans Affairs (VA) health care system. This occurred while Congress was focused on reducing wait times for veterans receiving care at the $V A$.

Congress passed the Veterans Access, Choice, and Accountability Act on August 7 , 2014, leading to the creation of the Veterans Choice Program. Legislators felt there were inappropriate delays in care at the VA, and the Choice program was meant to address this problem and provide an "apples-to-apples comparison [of the VA] with non-VA hospitals." ${ }^{3}$

Congress acknowledged the importance of curing HCV in the veteran population and allocated $\$ 1.5$ billion for fiscal year (FY) 2016 for DAAs. The VA Central Office (VACO) carefully monitored these resources. The first policy memorandum from VACO for HCV care, issued on May 21, 2015, recommended that the sickest patients who will benefit from the treatment "receive priority over those who are less ill." 4,5 Those who met criteria for advanced liver disease were prioritized for treatment at the VA, while those who did not meet criteria were given the option of receiving treatment through Choice, or waiting for a change in policy. ${ }^{6}$ Over time, revisions to the guidelines relaxed the criteria for VA treatment eligibility, and on February 24, 2016, all restrictions on HCV treatment at the VA were lifted..$^{7,8}$

The aim of this study was to provide a comparison of VA and non-VA care, specifically to determine whether care provided through Choice was timelier and more cost effective than care provided by the VA, and whether there was a quality difference. The high prevalence among veterans, wellestablished standards of care, and finite treatment course with clear indicators of success and failure makes HCV treatment an ideal disease with which to make this comparison.

\section{METHODS}

We retrospectively analyzed the VA electronic health records of all veterans seen in the VA Loma Linda Healthcare System (VALLHCS) Hepatology clinic for chronic HCV infection during FY 2016 who were referred to Choice for HCV treatment. One hundred veterans met these criteria, encompassing the Choice population; 71 were seen at least once by a non-VA (Choice) health care provider (HCP) and 61 completed a treatment regimen through Choice. Treatment completion was defined as cessation of medication 
TABLE 1 Statistical Analysis Results

\begin{tabular}{|c|c|c|c|c|c|}
\hline Variables & $\begin{array}{c}\text { No. VA } \\
\text { Group/Total }\end{array}$ & $\begin{array}{l}\text { VA Group, } \\
\text { mean }\end{array}$ & $\begin{array}{l}\text { No. Choice } \\
\text { Group/Total }\end{array}$ & $\begin{array}{l}\text { Choice Group, } \\
\text { mean }\end{array}$ & $P$ value \\
\hline Fibrosis-4 score & -- & 3.4 & -- & 1.94 & $<.001$ \\
\hline Platelet count & -- & $158 \times 10^{9} / \mathrm{L}$ & -- & $228 \times 10^{9} / L$ & $<.001$ \\
\hline Corrected platelets ${ }^{a}$ & $88 / 100$ & $170 \times 10^{9} / \mathrm{L}$ & -- & $228 \times 10^{9} / \mathrm{L}$ & $<.001$ \\
\hline Patients with cirrhosis & $74 / 100$ & -- & $3 / 100$ & -- & $<.001$ \\
\hline $\begin{array}{l}\text { Patients with medical } \\
\text { comorbidities }\end{array}$ & $52 / 100$ & -- & $22 / 100$ & -- & $<.001$ \\
\hline $\begin{array}{l}\text { Patients with mental health } \\
\text { comorbidities }\end{array}$ & $41 / 100$ & -- & $35 / 100$ & -- & .385 \\
\hline Patients with social issues & $35 / 100$ & -- & $16 / 100$ & -- & .002 \\
\hline Wait time, d & -- & 28.6 & -- & 42.3 & $<.001$ \\
\hline SVR12 (\%) & $296 / 320(93)^{b}$ & -- & $50 / 55(91)$ & -- & .613 \\
\hline
\end{tabular}

Abbreviations: SVR12, sustained virologic response at 12 weeks; VA, US Department of Veterans Affairs.

a12 lowest platelet counts removed from the VA group.

bVA group includes all veterans treated at the Veterans Affairs Loma Linda Healthcare System.

after the planned duration of therapy, or early termination of medication without resumption by that HCP. The Choice population was matched to an equal number of veterans who received HCV treatment from VALLHCS HCPs.

Data collected included age, gender, HCV genotype, determinants of liver fibrosis, and treatment success (defined as sustained virologic response at 12 weeks after the last dose of medication [SVR12]). Determinants of liver fibrosis included documented cirrhosis or complications of cirrhosis, Fibrosis-4 score (Fib-4), and platelet count.

Treatment failures were categorized as nonresponse (defined as detectable HCV viral load at the end of treatment), relapse (defined as an undetectable HCV viral load at the end of treatment with a subsequent positive test), and early termination (defined as a failure to complete the planned treatment regimen). Documented patient nonadherence, medical comorbidities that affected the treatment protocol, mental health diagnoses, and active social issues (defined as active or history of heavy alcohol use, active or history of illicit drug use, lack of social support, and homelessness) were noted.

Timeliness of delivery of care was measured in days. For the VA group, the wait time was defined as the date the consult for HCV treatment was placed to the date of the initial appointment with the HCV treatment provider. For the Choice group, the wait time was defined as the date the referral to the Choice program was made to the date of the initial appointment with the Choice HCP. Treatment regimens were evaluated for appropriateness based on guidelines from VACO and the American Association for the Study of Liver Diseases. ${ }^{9-11}$

Tests performed by Choice providers were evaluated for whether they were relevant to $\mathrm{HCV}$ care and whether similar data already were available from VALLHCS. Tests that were not indicated were identified as unnecessary costs incurred by the Choice program, as were tests that had to be repeated at the VA because of a lack of documentation from the Choice provider. All medications given inappropriately were considered added costs. Medicare reimbursement rates for the most applicable Current Procedural Terminology (CPT) code and VA national contract pricing for medications were used for calculations. This study was approved by the VALLHCS institutional review board.

\section{Statistical Analysis}

IBM (Armonk, NY) Statistical Package for Social Sciences software was used to evaluate for differences in Fib-4, platelet count, prevalence of cirrhosis, prevalence of 
TABLE 2 Patient Population Characteristics

\begin{tabular}{lccc} 
Characteristics & $\begin{array}{c}\text { Total VALLHCS, No. (\%) } \\
(\mathbf{n}=\mathbf{3 2 0})^{\mathrm{a}}\end{array}$ & $\begin{array}{c}\text { VA Group, \% } \\
(\mathbf{n}=\mathbf{1 0 0 )}\end{array}$ & $\begin{array}{c}\text { Choice Group, \% } \\
(\mathbf{n}=\mathbf{1 0 0 )}\end{array}$ \\
\hline Mean age, y & 65.2 & 61.6 \\
\hline Male gender & $244(75)$ & 97 & 96 \\
\hline Genotype 1 & $161(49)$ & 55 & 79 \\
\hline Genotype 1a & $83(25)$ & 24 & 19 \\
\hline Genotype 1b & $42(13)$ & 9 & 14 \\
\hline Genotype 2 & $36(11)$ & 4 & 5 \\
\hline Genotype 3 & $4(1)$ & 1 & 0 \\
\hline Genotype 4 & 0 & 0 & 0 \\
\hline Genotype 5 & 0 & 0 & 2
\end{tabular}

Abbreviations: VA, US Department of Veterans Affairs; VALLHCS, VA Loma Linda Healthcare System.

a6 Veterans were infected with 2 different genotypes of HCV.

medical comorbidities, prevalence of mental health comorbidities, prevalence of the social issues defined in the Methods section, time from referral to time of appointment date, and SVR12 rate between the VA and Choice groups.

\section{Exclusions}

There were 15 veterans in the VA group who had a wait time of $>100$ days. Of these, $5(33 \%)$ were initially Choice referrals, but due to negative interactions with the Choice provider, the veterans returned to VALLHCS for care. Two of the $15(13 \%)$ did not keep appointments and were lost to follow up. Six of the $15(40 \%)$ had medical comorbidities that required more immediate attention, so HCV treatment initiation was deliberately moved back. The final 2 veterans scheduled their appointments unusually far apart, artificially increasing their wait time. Given that these were unique situations and some of the veterans received care from both Choice and VA providers, a decision was made to exclude these individuals from the study.

It has been shown that platelet count correlates with degree of liver fibrosis, a concept that is the basis for the Fib-4 scoring system. ${ }^{12}$ Studies have shown that platelet count is a survival predictor in those with cirrhosis, and thrombocytopenia is a negative predictor of $\mathrm{HCV}$ treatment success using peginterferon and rib- avirin. ${ }^{13,14}$ Therefore, the VA memorandum automatically assigned the sickest individuals to the VA for HCV treatment. The goal of this study was to compare the impact of factors other than stage of fibrosis on HCV treatment success, which is why the 12 veterans with platelet count $<100,000$ in the VA group were excluded. There were no veterans with platelet count $<100,000$ in the Choice group.

When comparing SVR12 rates between the VA and Choice groups, every veteran treated at VALLHCS in FY 2016 was included, increasing the number in the VA group from 100 to 320 and therefore the power of this comparison.

\section{RESULTS}

A summary of the statistical analysis can be found in Table 1. The genotype distribution was consistent with epidemiological studies, including those specific to veterans. ${ }^{15,16}$ There were statistically significant differences $(P<.001)$ in mean Fib-4 and mean platelet count. The VA group had a higher Fib-4 and lower platelet count. Seventy-four percent of the VA population was defined as cirrhotic, while only $3 \%$ of the Choice population met similar criteria $(P<.001)$. The VA and Choice groups were similar in terms of age, gender, and genotype distribution (Table 2).

The VA group was found to have a higher prevalence of comorbidities that affected HCV treatment. These conditions included but were not limited to: chronic kidney disease that precluded the use of certain medications, any condition that required medication with a known interaction with DAAs (ie, proton pump inhibitors, statins, and amiodarone), and cirrhosis if it impacted the treatment regimen. The difference in the prevalence of mental health comorbidities was not significant $(P=.39)$, but there was a higher prevalence of social issues among the VA group $(P=.002)$.

The mean wait time from referral to appointment was 28.6 days for the VA group and 42.3 days for the Choice group $(P<.001)$, indicating that a Choice referral took longer to complete than a referral within the VA for HCV treatment. Thirty of the $71(42 \%)$ veterans seen by a Choice provider accrued extraneous cost, with a mean additional cost of $\$ 8,561.40$ per veteran. In the Choice group, 61 veterans completed a treatment regimen with the Choice HCP. Fifty-five veterans completed treatment and had available SVR12 data (6 were 
lost to follow up without SVR12 testing) and $50(91 \%)$ had confirmed SVR12. The charts of the 5 treatment failures were reviewed to discern the cause for failure. Two cases involved early termination of therapy, 3 involved relapse and 2 failed to comply with medication instructions. There was 1 case of the Choice HCP not addressing simultaneous use of ledipasvir and a proton pump inhibitor, potentially causing an interaction, and 1 case where both the VA and Choice providers failed to recognize indicators of cirrhosis, which impacted the regimen used.

In the VALLHCS group, records of 320 veterans who completed treatment and had SVR12 testing were reviewed. While the Choice memorandum was active, veterans selected to be treated at VALLHCS had advanced liver fibrosis or cirrhosis, medical and mental health comorbidities that increased the risk of treatment complications or were considered to have difficulty adhering to the medication regimen. For this group, 296 (93\%) had confirmed SVR12. Eighteen of the $24(75 \%)$ treatment failures were complicated by nonadherence, including all 13 cases of early termination. One patient died from complications of decompensated cirrhosis before completing treatment, and 1 did not receive $\mathrm{HCV}$ medications during a hospital admission due to poor coordination of care between the VA inpatient and outpatient pharmacy services, leading to multiple missed doses.

The difference in SVR12 rates (ie, treatment failure rates), between the VA and Choice groups was not statistically significant $(P=.61)$. None of the specific reasons for treatment failure had a statistically significant difference between groups. A treatment failure analysis is shown in Table 3, and Table 4 indicates the breakdown of treatment regimens.

\section{DISCUSSION}

The Veterans Health Administration (VHA) is the largest integrated health care system in the US, consisting of 152 medical centers and $>1,700$ sites of care. The VA has the potential to meet the health care needs of 21.6 million veterans. About 9 million veterans are enrolled in the VA system and 5.9 million received health care through VHA. ${ }^{17}$ However, every medical service cannot realistically be made available at every facility, and some veterans have difficulty gaining access to VHA care; distance and wait
TABLE 3 Treatment Failure Analysis

\begin{tabular}{|c|c|c|}
\hline Failures & $\begin{array}{l}\text { Total VALLHCS, No. } \\
\qquad(n=320)\end{array}$ & $\begin{array}{l}\text { Choice Group, No. } \\
\text { (n= }=55)\end{array}$ \\
\hline Failures $(P=.61)$ & 24 & 5 \\
\hline Early termination of therapy $(P=.88)$ & 13 & 2 \\
\hline Nonresponse to therapy & 0 & 0 \\
\hline Relapse following therapy $(P=.47)$ & 10 & 3 \\
\hline Inappropriate regimen used & 0 & 1 \\
\hline Veteran nonadherence $(P=.96)$ & 18 & 2 \\
\hline Choice system failure & NA & 3 \\
\hline VA system failure & 1 & 1 \\
\hline Other & 1 & 0 \\
\hline
\end{tabular}

Abbreviations: VA, US Department of Veterans Affairs; VALLHCS, VA Loma Linda Healthcare System.

times have been well-publicized issues that need further exploration. ${ }^{18,19}$ The Choice program is an attempt to meet gaps in VA coverage using non-VA HCPs.

$\mathrm{HCV}$ infection is a specific diagnosis with national treatment guidelines and wellstudied treatments; it can be cured, with an evidence-based definition of cure. The VACO policy memorandum to refer less sick veterans to Choice while treating sicker veterans at the VA provided the opportunity to directly compare the quality of the 2 programs. The SVR12 rates of VALLHCS and Choice providers were comparable to the national average at the time, and while the difference in SVR12 rate was not significant, VALLHCS treated a significantly higher number of patients with cirrhosis because of the referral criteria. ${ }^{20}$

The significant difference in medical comorbidities between the VA and Choice groups was not surprising, partly because of the referral criteria. Cirrhosis can impact the treatment regimen, especially in regard to use of ribavirin. Since the presence of mental health comorbidities did not affect selection into the Choice group, it makes sense that there was no significant difference in prevalence between the groups.

VACO allowed veterans with HCV treatment plans that VA HCPs felt were too complicated for the Choice program to be treated by VHA HCPs. ${ }^{9}$ VALLHCS exercised this right for veterans at risk for nonadherence, because in HCV treatment, nonadherence leads to treatment failure and 
TABLE 4 Distribution of Treatment Regimens

\begin{tabular}{|c|c|c|c|}
\hline Regimens & $\begin{array}{l}\text { Total VALLHCS, } \\
\text { No. }(\%) \\
(n=320)\end{array}$ & $\begin{array}{l}\text { VA Group, } \\
\text { No. (\%) } \\
(n=100)\end{array}$ & $\begin{array}{c}\text { Choice Group, } \\
\text { No. (\%) } \\
\text { (n= 61) }\end{array}$ \\
\hline $\begin{array}{l}\text { Ombitasvir/paritaprevir/ } \\
\text { ritonavir/dasabuvir }\end{array}$ & $6(2)$ & $6(6)$ & $9(15)$ \\
\hline $\begin{array}{l}\text { Ombitasvir/paritaprevir/ } \\
\text { ritonavir/dasabuvir and ribavirin }\end{array}$ & $18(6)$ & $14(14)$ & $13(21)$ \\
\hline Ledipasvir/sofosbuvir & $108(34)$ & $27(27)$ & $25(41)$ \\
\hline $\begin{array}{l}\text { Ledipasvir/sofosbuvir } \\
\text { and ribavirin }\end{array}$ & $58(18)$ & $33(33)$ & $4(7)$ \\
\hline Elbasvir/grazoprevir & $54(17)$ & $1(1)$ & 0 \\
\hline $\begin{array}{l}\text { Elbasvir/grazoprevir and } \\
\text { ribavirin }\end{array}$ & $2(1)$ & $2(2)$ & 0 \\
\hline Sofosbuvir and ribavirin & $34(11)$ & $9(9)$ & $7(11)$ \\
\hline Daclatasvir and sofosbuvir & $6(2)$ & $2(2)$ & $2(3)$ \\
\hline $\begin{array}{l}\text { Daclatasvir and sofosbuvir } \\
\text { and ribavirin }\end{array}$ & $33(10)$ & $6(6)$ & $1(2)$ \\
\hline Velpatasvir/sofosbuvir & $7(2)$ & 0 & 0 \\
\hline $\begin{array}{l}\text { Velpatasvir/sofosbuvir and } \\
\text { ribavirin }\end{array}$ & $4(1)$ & 0 & 0 \\
\hline
\end{tabular}

Abbreviations: VA, US Department of Veterans Affairs; VALLHCS, VA Loma Linda Healthcare System. sending the package to Triwest Healthcare Alliance, a private insurance processor contracted with the VA. Triwest selects the Choice provider, often without any input from the VA, and arranges the veteran's initial appointment. ${ }^{22}$ Geographic distance to the veteran's address is the main selection criteria for Triwest. Documents sent between the Choice and VA HCPs go through the Office of Community Care and Triwest. This significantly increases the potential for delays and failed communication. Triwest had a comprehensive list of providers deemed to be qualified to treat HCV within the geographic catchment of VALLHCS. This list was reviewed, and all veterans referred to Choice had HCPs near their home address; therefore, availability of Choice HCPs was not an issue.

The VA can provide guidance on management of the veteran in the form of bundle packages containing a list of services for which the Choice provider is authorized to provide, and ones the Choice provider is not authorized to provide. Some Choice HCPs ordered tests that were not authorized for HCV treatment such as esophagogastroduodenoscopy, colonoscopy, and liver biopsy. In all, 17 of 71 (24\%) veterans seen by Choice HCPs had tests performed or ordered that VA HCPs would not have obtained for the purpose of HCV treatment (Table 5).

In order to prevent veterans from receiving unnecessary tests, a VALLHCS hepatologist asked to be notified by VA administrators overseeing Choice referrals whenever a secondary authorization request (SAR) was submitted by a Choice HCP. This strategy is not standard VA practice, therefore at many VA sites these requested tests would have been performed by the Choice HCP, which is why SARs were factored into cost analysis.

SVR12 test results that were drawn too early and had to be repeated at VALLHCS were a cost unique to the Choice program. Duplicate tests, particularly imaging studies and blood work, were extraneous costs. The largest extraneous costs were treatment regimens prescribed by Choice HCPs that did not follow standard of care and required VA provider intervention. Thirty of the $71(42 \%)$ veterans seen by a Choice provider accrued a mean $\$ 8,561.40$ in extra costs. As a result, the Choice program cost VHA $\$ 250,000$ more to provide care for 30 veterans (enough to pay for a physician's annual salary). 
Some inappropriate treatment regimens were the result of Choice HCP error, such as 1 case in which a veteran was inadvertently switched from ledipasvir/sofosbuvir to ombitasvir/paritaprevir/ritonavir/dasabuvir after week 4. The veteran had to start therapy over but still achieved SVR12. Other cases saw veterans receive regimens for which they had clear contraindications, such as creatinine clearance $<30 \mathrm{~mL} / \mathrm{min} / 1.73 \mathrm{~m}^{2}$ for sofosbuvir or a positive resistance panel for specific medications. Eleven of $62(18 \%)$ veterans who were started on HCV treatment by a Choice HCP received a regimen not consistent with VA guidelines - an alarming result.

Follow up for veterans referred to Choice was extremely labor intensive, and assessment of personnel requirements in a Choice-based VA system must take this into consideration. The Choice HCP has no obligation to communicate with the VA HCP. At the time of chart review, 57 of $71(80 \%)$ Choice veterans had inadequate documentation to make a confident assessment of the treatment outcome. Multiple calls to the offices of the Choice HCP were needed to acquire records, and veterans had to be tracked down for additional tests. Veterans often would complete treatment and stop following up with the Choice provider before SVR12 confirmation. The VA hepatology provider reviewing Choice referrals served as clinician, case manager, and clerk in order to get veterans to an appropriate end point in their hepatitis $C$ treatment, with mostly unmeasured hours of work.

\section{Limitations}

The study population size was limited by the number of veterans able to complete treatment through Choice. The parameters in the VACO policy memos automatically selected the VA and Choice groups but made them clinically distinct populations. New treatment medications were released during the study period, which impacted management strategy. Occasionally, VA and nonVA HCPs preferred different treatment regimens, leading to variation in the distribution of regimens used despite similar genotype distribution (Tables 2 and 4). In addition, a retrospective study is at risk for recall bias. A prospective study randomizing veterans to the Choice and VA groups is an important future endeavor. Comparing veteran satisfaction for Choice and VA services is also crucial.

\section{TABLE 5 Quality of Care Issues}

- $24 \%$ (17 of 71 ) veterans seen by Choice Act health care providers had tests performed or ordered that VA providers did not recommend in their pre-referral assessment, or had already been performed at the VA prior to referral.

- $18 \%$ (11 of 62 ) veterans initiated on hepatitis $C$ treatment by Choice health care providers received a regimen not consistent with VA practice guidelines at the time.

- $42 \%$ (30 of 71 ) veterans seen by a Choice health care provider accrued costs unique to the Choice program, either from duplicate or unnecessary tests or inappropriate medication regimens, with an average cost of $\$ 8,561.40$.

- $80 \%$ (57 of 71 ) veterans seen by a Choice health care provider had inadequate documentation to communicate transpired events in the VA electronic medical record, at the time of chart review.

\section{CONCLUSIONS}

This study demonstrates that the VA was able to provide more cost-effective and more timely care for HCV treatment to a relatively sicker population with no reduction in treatment success when compared with non-VA HCPs through the Choice program. While the Choice program can help veterans receive services they may otherwise not have access to and reduce travel time, the current system introduces inefficiencies that delay care and decrease cost-effectiveness. The Choice HCP selection process is based on proximity rather than quality, which may place the veteran at risk for receiving substandard care. Large-scale quality of care studies that compare efficiency measures, clinical outcomes, patient demographics, travel distance, cost efficacy and patient satisfaction for veterans receiving similar services at a VA facility and through Choice should be performed to ensure that veterans receive the best care available.

Author Disclosures

The authors report no actual or potential conflicts of interest with regard to this article.

\section{Disclaimer}

The opinions expressed herein are those of the authors and do not necessarily reflect those of Federal Practitioner, Frontline Medical Communications Inc., the US Government, or any of its agencies. This article may discuss unlabeled or investigational use of certain drugs. Please review the complete prescribing information for specific drugs or drug combinations - including indications, contraindications, warnings, and adverse effects - before administering pharmacologic therapy to patients.

\section{References}

1. Denniston MM, Jiles RB, Drobeniuc J, et al. Chronic hepatitis $C$ virus infection in the United States, National Health and Nutrition Examination Survey 2003 to 2010. Ann Intern Med. 2014;160(5):293-300. doi:10.7326/M13-1133

2. Dominitz JA, Boyko EJ, Koepsell TD, et al. Elevated prevalence of hepatitis $C$ infection in users of United States veterans medical centers. Hepatology. 2005;41(1):88-96. doi:10.1002/hep.20502

3. Veterans Access, Choice, and Accountability Act of 2014. 42 USC $\$ 1395$ (2014).

4. Tuchschmidt J. Attachment C: Provision of hepatitis $C$ treatment. US Department of Veterans Affairs Central Of- 
fice Memorandum from the Principal Deputy Under Secretary for Health. http://vaww.hepatitis.va.gov/education /choice-provision-hcv-treatment.asp. Published May 21, 2015. [Nonpublic site.]

5. Tuchschmidt J. Attachment A: Provision of hepatitis C (HCV) treatment through the Choice program. US Department of Veterans Affairs Central Office Memorandum from the Principal Deputy Under Secretary for Health. http:// vaww.hepatitis.va.gov/pdf/choice-attachment-a-FY16 .pdf. Published May 21, 2015. [Nonpublic site.]

6. Tuchschmidt J. Attachment B: Initiation of hepatitis $C$ virus (HCV) treatment: protocol for prioritization. US Department of Veterans Affairs Central Office Memorandum from the Principal Deputy Under Secretary for Health. http://vaww .hepatitis.va.gov/pdf/provision-HCV-treatment-attach ment-b.pdf. Published May 21, 2015. [Nonpublic site.]

7. Murphy, JP. Hepatitis $C$ virus funding and prioritization status. US Department of Veterans Affairs Central Office Memorandum from the Assistant Deputy Under Secretary for Health for Clinical Operations. http://vaww.hepatitis .va.gov/education/choice-memo-hcv-funding-and -prioritization-status-01272016.asp. Published January 27, 2016. [Nonpublic site.]

8. Lynch TJ, McCarthy MF. Hepatitis C virus funding and prioritization status update. US Department of Veterans Affairs Central Office Memorandum from the Assistan Deputy Under Secretary for Health for Clinical Operations and Acting Assistant Deputy Under Secretary for Health for Patient Care Services. http://vaww.hepatitis.va.gov /education/choice-funding-update-feb-2016.asp. Published February 24, 2016. [Nonpublic site.]

9. Morgan TR, Yee H; US Department of Veterans Affairs National Hepatitis C Resource Center Program and the National Viral Hepatitis Program in the Office of Patient Care Services. Chronic hepatitis $\mathrm{C}$ virus (HCV) infection: treatment considerations. http://vaww.hepatitis.va.gov /pdf/treatment-considerations-2016-03-28.pdf. Published March 28, 2016. [Nonpublic site.]

10. American Association for the Study of Liver Diseases; Infectious Diseases Society of America. Initial Treatment Box. http://hcvguidelines.org/full-report/initial-treatment -box-summary-recommendations-patients-who-are -initiating-therapy-hcv. Updated November 6, 2019. Accessed May 11, 2020

11. AASLD/IDSA HCV Guidance Panel. Hepatitis $C$ guidance: AASLD-IDSA recommendations for testing, managing, and treating adults infected with hepatitis $\mathrm{C}$ virus. Hepatology. 2015;62(3): 932-954. doi:10.1002/hep.27950

12. Sterling RK, Lissen $E$, Clumeck $N$, et al. Development of a simple noninvasive index to predict significant fibrosis in patients with HIV/HCV coinfection. Hepatology. 2006; 43(6):1317-1325. doi:10.1002/hep.21178
13. Realdi G, Fattovich G, Hadziyannis $S$, et al. Survival and prognostic factors in 366 patients with compensated cirrhosis type B: a multicenter study. The Investigators of the European Concerted Action on Viral Hepatitis (EUROHEP). J Hepatol. 1994;21(4):656-666. doi:10.1016/s0168 $-8278(94) 80115-0$

14. Kanda T, Kato K, Tsubota A, et al. Platelet count and sustained virological response in hepatitis $\mathrm{C}$ treatment. World J Hepatol. 2013;5(4):182-188. doi:10.4254/wjh.v5.i4.182

15. Manos MM, Shvachko VA, Murphy RC, Arduino JM, Shire NJ. Distribution of hepatitis $C$ virus genotypes in a diverse US integrated health care population. J Med Virol. 2012;84(11):1744-1750. doi:10.1002/jmv.23399

16. Cheung RC. Epidemiology of hepatitis $C$ virus infection in American veterans. Am J Gastroenterol. 2000;95(3): 740-747. doi:10.1111/j.1572-0241.2000.01854.x

17. Bagalman $E$. The number of Veterans that use VA health care services: a fact sheet. Congressional Research Service Report R43579. https://fas.org/sgp/crs/misc/R43579.pdf. Published June 3, 2014. Accessed May 11, 2020.

18. US General Accounting Office. Report to the Ranking Minority Member, Subcommittee on Compensation, Pension, Insurance, and Memorial Affairs, Committee on Veterans' Affairs, US House of Representatives. How distance from VA facilities affects veterans' use of VA services. https:// www.gao.gov/assets/230/221992.pdf. Published December 1995. Accessed May 11, 2020.

19. Bronstein S, Griffin D. A fatal wait: Veterans languish and die on a VA hospital's secret list. http://www.cnn .com/2014/04/23/health/veterans-dying-health-care -delays/index.html. Published April 23, 2014. Accessed May 11, 2020.

20. Ioannou GN, Beste LA, Chang MF, et al. Effectiveness of sofosbuvir, ledipasvir/sofosbuvir, or paritaprevir/ritonavir/ombitasvir and dasabuvir regimens for treatment of patients with hepatitis $C$ in the Veterans Affairs national health care system. Gastroenterology. 2016;151(3):457471. doi:10.1053/j.gastro.2016.05.049

21. Malespin $\mathrm{MH}$, Harris $\mathrm{C}$, Kanar $\mathrm{O}$, et al. Barriers to treatment of chronic hepatitis $\mathrm{C}$ with direct acting antivirals in an urban clinic. Ann Hepatol. 2019;18(2):304-309. doi:10.1016/j.aohep.2018.06.001

22. Tuchschmidt J. Attachment D: Hepatitis C virus (HCV) fact sheet for Veterans Choice Program for both VA and Choice providers. US Department of Veterans Affairs Central Office Memorandum from the Deputy Under Secretary for Health for Policy and Services and the Acting Deputy Undersecretary for Health for Operations and Management. http://vaww .hepatitis.va.gov/educatiochoice-provision-HCV-treatment -additional.asp. [Nonpublic site.] 